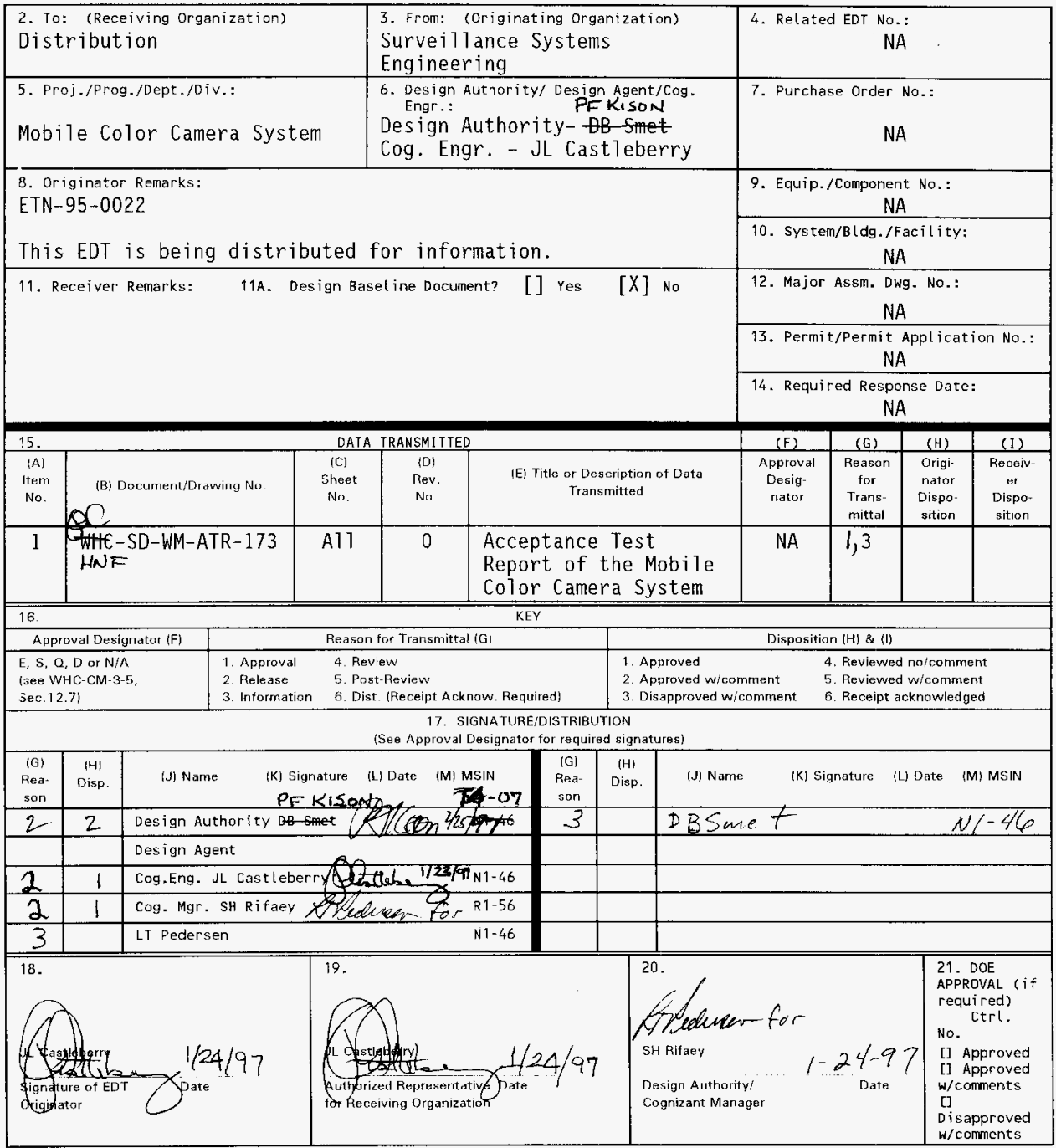




\section{Acceptance Test Report of the Mobile Color Camera System}

\section{J.L. Castleberry}

Lockheed Martin Hanford Co., Richland, WA 99352

U.S. Department of Energy Contract DE-AC06-96RL13200

$\begin{array}{lll}\text { EDT/ECN: } & \text { EDT-617454 } & \text { UC: } 2070 \\ \text { Org Code: } 74720 & \text { Charge Code: } & \text { E51784 } \\ \text { B\&R Code: } & \text { EW3120074 } & \text { Total Pages: } 44\end{array}$

Key Words: Purge, Electrical Safety Control Panel (ESCP), Mobile Color Camera System (MCCS)

Abstract: The purpose of this report is to present test data recorded during acceptance testing of the Mobile Color Camera System (MCCS).

Panasonic is a trademark of Matsushita Electric Industrial Vitis II is a trademark of R.J. Electronics Co.

TRADEMARK DISCLAIMER. Reference herein to any specific comercial product, process, or service by trade name, tradenark, manufacturer, or otherwise, does not necessarily constitute or imply its endorsement, recommendation, or favoring by the United States Government or any agency thereof or its contractors or subcontractors.

Printed in the United States of America. To obtain copies of this document, contact: Document Control Services, P.O. Box 950, Mailstop H6-08, Richland WA 99352, Phone (509) 372-2420;

Fax (509) 376-4989.
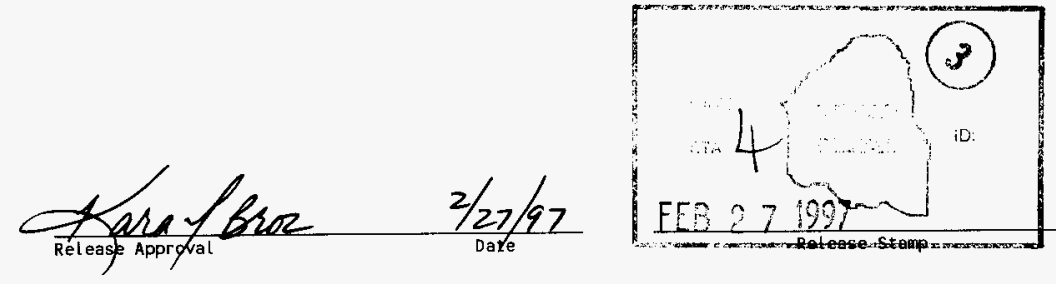

\section{Approved for Public Release}




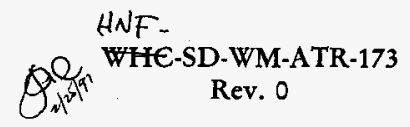

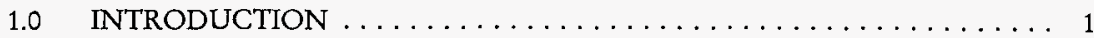

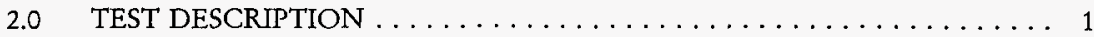

3.0 TEST METHOD AND TEST EQUIPMENT $\ldots \ldots \ldots \ldots \ldots \ldots \ldots \ldots \ldots \ldots$

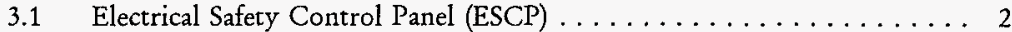

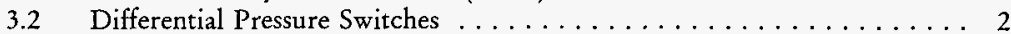

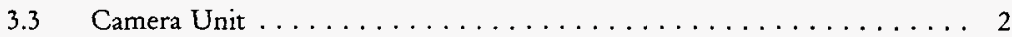

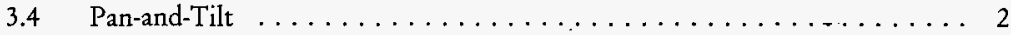

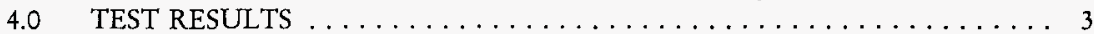

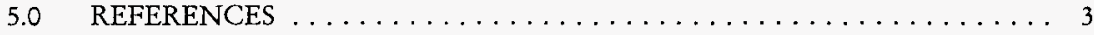

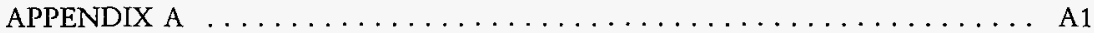

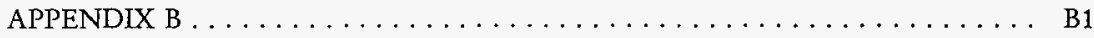

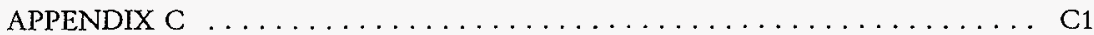


XYFC-SD-WM-ATR-173

HNF Rev. 0

\subsection{INTRODUCTION}

This Acceptance Test Report is being generated to provide test data from Acceptance Test Procedure WHC-SD-WM-ATP-173, Rev. 0 . This acceptance test was developed and performed to acceptance test the Mobile Color Camera System (MCCS). The MCCS consists of a camera enclosure, pan-and-tilt unit, deployment cable, field control unit, mobile platform, and electrical safety control panel. The MCCS is purged and pressurized in accordance with NFPA 496 type X systems for use in Class 1, Division 1 hazardous locations. The Electrical Safety Control Panel (ESCP) ensures pressure is present before system power is provided to the components located in a hazardous location. The ESCP also provides automatic shutdown of electrical components located in a hazardous location in the event that the protective air supply is interrupted. The ESCP was procured and qualified as a safety SSC. This item is designated safety significant in accordance with WHC-IP-0842 Volume IV, Section 5.9. The remainder of the MCCS is classified as general service equipment. Test data is provided in the APPENDIX section of this report. Appendix A is a copy of the ATP, WHC-SD-WM-ATP-173, Rev. 0 included here for information. APPENDIX B contains test data of the individual MCCS units that were tested per the acceptance test. APPENDIX $\mathrm{C}$ consists of temperature test data provided by the camera/light assembly manufacturer.

\subsection{TEST DESCRIPTION}

Individual MCCS units were acceptance tested per WHC-SD-WM-ATP-173, Rev. O. The camera and camera control unit were identified by individual serial numbers. The Electrical Control Safety Panels were also identified per individual serial numbers. Each system was functionally tested in full configuration and within system operating

parameters. The acceptance test documents that the camera functions, light, control units, positioning device, purge system, and electrical safety shutdown system for each MCCS operate according to the functional design criteria referenced in WHC-SD-WM-ETP-135, Rev. 1.

\subsection{TEST METHOD AND TEST EQUIPMENT}

The MCCS was tested in its full configuration. Overall functionality was checked to ensure all components worked together as a whole. This was accomplished by fully interconnecting the system and running it through all phases of operation. System flow measurements were taken with a calibrated flow meter and system pressure measurements were taken with a calibrated pressure gauge. 


\section{WHE-SD-WM-ATR-173 \\ HNF Rev. 0}

\subsection{Electrical Safety Control Panel (ESCP)}

Each ESCP was functionally tested to verify that control functions and display/indicator functions operate properly. This was accomplished per sections 2.1, 2.2, and 2.3, and 2.4 of Acceptance Test Procedure, WHC-SDWM-ATP-173, Rev.O. Pressure and flow readings were taken during the purge operation of the system to verify that proper flow and pressure were present during operation. All pressure and flow measurements were taken with calibrated equipment.

\subsection{Differential Pressure Switches}

Two differential pressure $(\mathrm{dp})$ switches are located within the camera housing. The dp switches were acceptance tested in Section 2.3 of WHC-SD-WM-ATP173 , Rev. 0 . The dp switches are set at .22 psi ( 6 in. w.g.). The dp switches are used to monitor the difference in pressure between the MCCS enclosures and atmospheric pressure. In order to qualify as Type X purge protected in accordance with NFPA 496-1993, a minimum pressure differential of at least $25 \mathrm{~Pa}$ (0.1 in. w.g.) must be maintained. If inadequate pressure exists, the dp switches transmit a signal to the ESCP which then de-energizes the camera, light, and pan-and-tilt.

\subsection{Camera Unit}

The camera and all of its functions were tested in accordance with Section 2.4 of WHC-SD-WM-ATP-173, Rev.0. This section takes the camera through a functional test of the auto focus, manual focus, zoom, and auto iris. A broadcast industry standard resolution chart was used to check camera image resolution. Also tested per Section 2.4 was the maximum distance the camera could resolve a $1 / 32$ inch black line and a 1 inch black square on an $18 \%$ neutral gray background using only the system lighting.

\subsection{Pan-and-Tilt}

Full range testing of the pan-and-tilt was performed in accordance with Section 2.5 of WHC-SD-WM-ATP-173, Rev. 0. The maximum tilt ranges were recorded as were the maximum pan ranges. The total ranges were derived for both pan and tilt per the recorded values. Also tested was the ability of the pan-and-tilt to fail safe upon system loss of power . 


\section{WHe-SD-WM-ATR-173 \\ HNF Rev. $O$}

\subsection{TEST RESULTS}

All test results were recorded on the test data sheets specified in WHC-SD-WM-ATP-173, Rev. 0 for each individual system. A copy of the test data for each individual system is provided in APPENDIX B of this test report. APPENDIX C contains temperature test data from the lights to document that the external temperature of the light housing does not exceed $416^{\circ} \mathrm{C}\left(774^{\circ} \mathrm{F}\right)$ which is $80 \%$ of the autoignition temperature of hydrogen. This data was provided by the camera/light assembly manufacturer.

\subsection{REFERENCES}

1. WHC-S-0447, Rev. 1, "Procurement Specification for Electrical Safety Control Panel for the Mobile Color Camera System".

2. Purchase Order \#W472051-GS, "RCS-2015 - S-Video Gas Purged In-Tank Camera Inspection System".

3. WHC-SD-WM-ETP-135, Rev. 1, "Engineering Task Plan for the Mobile Color Camera System".

4. WHC-SD-WM-ATP-173, Rev. 0, "Acceptance Test Procedure of the Mobile Color Camera System.

5. Unreviewed Safety Question Evaluation - Farley 1996, TF-95-0103, "Video In Hanford Waste Tanks Using the Mobile Color Camera System".

6. WHC-SD-WM-SCH-002 - Braun 1996, Rev. O, "Safety Classification of the Mobile Color Camera System".

7. WHC-SD-WMN-DRR-054 - Webb 1996, Rev. O, "Design Review Report for the 60\% Design Review of the Mobile Color Camera System".

8. NFPA 77, "Standard Practices for Static Electricity"

9. NFPA 496, "Standard for Purged and Pressurized Enclosures for Electrical Equipment". 
WHE-SD-WM-ATR-173

HNF Rev. 0

APPENDIX A

\section{ACCEPTANCE TEST PROCEDURE}


WHC-SD-WM-ATR-173 REV. 0

HNF

\section{ACCEPTANCE TEST PROCEDURE MOBILE COLOR CAMERA SYSTEM}

Surveillance Systems Integration

May, 1996 


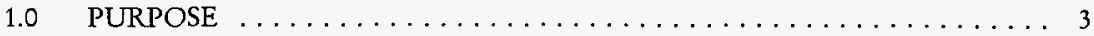

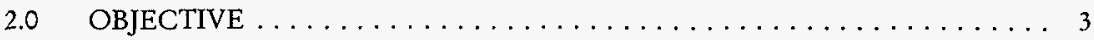

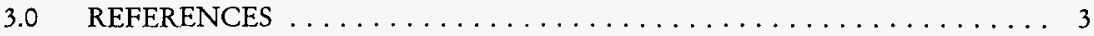

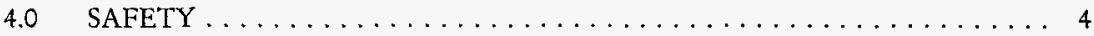

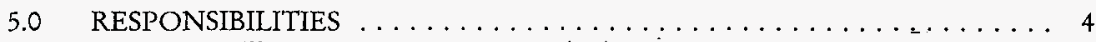

5.1 Surveillance Systems Integration (SSI) $\ldots \ldots \ldots \ldots \ldots \ldots \ldots \ldots$

5.2 WHC Quality Control (QC) $\ldots \ldots \ldots \ldots \ldots \ldots \ldots \ldots \ldots$

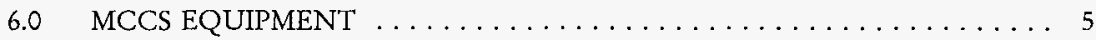

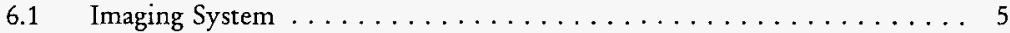

7.0 TEST CONDITIONS AND EQUIPMENT REQUIRED $\ldots \ldots \ldots \ldots \ldots \ldots$

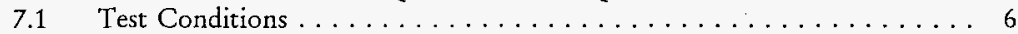

7.2 Test Equipment $\ldots \ldots \ldots \ldots \ldots \ldots \ldots \ldots \ldots \ldots \ldots \ldots \ldots \ldots \ldots \ldots$

8.0 ACCEPTANCE TEST $\ldots \ldots \ldots \ldots \ldots \ldots \ldots \ldots \ldots \ldots \ldots \ldots \ldots \ldots \ldots$

9.0 DOCUMENTATION $\ldots \ldots \ldots \ldots \ldots \ldots \ldots \ldots \ldots \ldots \ldots \ldots$

9.1 Test Records ..................... 7

10.0 Exceptions $\ldots \ldots \ldots \ldots \ldots \ldots \ldots \ldots \ldots \ldots \ldots \ldots \ldots$

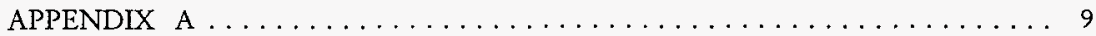

1.0 ACCEPTANCE TEST PROCEDURE $\ldots \ldots \ldots \ldots \ldots \ldots \ldots \ldots \ldots . \ldots \ldots$

1.1 PREREQUISITES $\ldots \ldots \ldots \ldots \ldots \ldots \ldots \ldots \ldots \ldots \ldots \ldots$

2.0 PROCEDURE STEPS $\ldots \ldots \ldots \ldots \ldots \ldots \ldots \ldots \ldots \ldots \ldots \ldots \ldots \ldots \ldots$

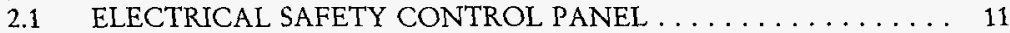

2.2 PURGE SYSTEM AND ESCP OPERATION $\ldots \ldots \ldots \ldots \ldots \ldots, 12$

2.3 DIFFERENTIAL PRESSURE SWITCHES $\ldots \ldots \ldots \ldots \ldots \ldots, 13$

2.4 CAMERA UNIT $\ldots \ldots \ldots \ldots \ldots \ldots \ldots \ldots \ldots \ldots \ldots \ldots \ldots$

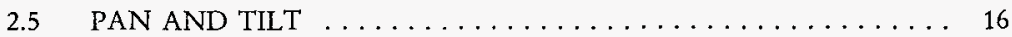

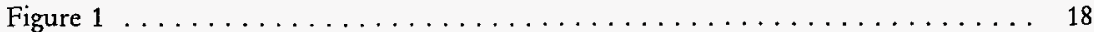


WHE-SD-WM-ATR-173 REV. 0

HNF

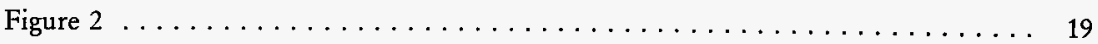

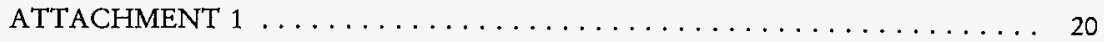




\subsection{PURPOSE}

Acceptance Test Procedure (ATP) will provide a documented means of verifying that all of the functional components of the Mobile Color Camera System (MCCS) operate properly when integrated. Specific steps are provided to verify that the pressurized safety system functions as designed to meet NFPA 496 Type X pressurization requirements. Successful completion of the ATP is a prerequisite for approving the MCCS for field use. All data points and approval signatures for this acceptance test will be recorded on Attachment 1. Attachment 1 will serve as a data/signature sheet which will allow acceptance testing of more than one MCCS with this procedure.

\subsection{OBJECTIVE}

The objective of this procedure is to demonstrate and document the acceptance and operability of the Mobile Color Camera System (MCCS). The camera focus, iris, and zoom remote controls will be functionally tested. The resolution of the camera will be verified using standard reference charts. The pan-and-tilt unit will be tested for required ranges of motion, and the camera lights will be functionally tested. The purge function of the camera will be functionally tested to verify that ten volumes of air are exchanged during purge cycle, and that pressure and flow exists during operation of the system. Electrical shutdown of system upon loss of pressure will be demonstrated. Differential pressure switches will be functionally tested for operability and redundancy to show that no single point failure exists in system electrical shut down. Volume calculations of MCCS will be attached to the Acceptance Test Report (ATR) as additional verification that ten purge volumes have been exchanged during purge cycle. Vendor provided temperature test data of the camera light housing will also be provided as an attachment to the ATR. Vendor provided temperature test data will document that light housing temperature is below the $80 \%$ auto-ignition temperature of hydrogen.

\subsection{REFERENCES}

- WHC-S-0447, Rev. 1, "Procurement Specification for Electrical Safety Control Panel for The Mobile Color Camera System".

- Purchase Order \#W472051-GS, "RCS-2015 - S-Video Gas Purged InTank Inspection System".

- WHC-SD-WM-ETP-135, Rev. 1, "Engineering Task Plan for The Mobile Color Camera System". 
- Unreviewed Safety Question Evaluation - Farley 1996, TF-95-0103, "Video In Hanford Waste Tanks Using The Mobile Color Camera System".

- WHC-SD-WM-SCH-002 - Braun 1996, Rev. O, "Safety Classification of Mobile Color Camera System".

- WHC-SD-WM-DRR-054 - Webb 1996, Rev. O, "Design Review Report for the $60 \%$ Design Review of the Mobile Color Camera System".

\subsection{SAFETY}

A pre-job meeting will be held prior to performing the ATP. Potential tripping hazards, lifting techniques and equipment safety issues will be addressed as part of the pre-job.

\subsection{RESPONSIBILITIES}

5.1 Surveillance Systems Integration (SSI)

SSI will provide the Test Engineer. The Test Engineer will ensure that all necessary preparations for this ATP have been completed prior to beginning the test. The Test Engineer will organize and give final direction for the test activities. The Test Engineer may be the Cognizant Engineer, or other SSI personnel familiar with the MCCS design. SSI will coordinate all of the arrangements necessary to perform the ATP. SSI will also generate an Acceptance Test Report upon completion of this ATP.

5.2 WHC Quality Control (QC)

WHC QC shall provide test witness personnel for this ATP. Witnesses are responsible for verifying that the requirements are met throughout the testing and to ensure documentation sequences of the ATP. This ATP is not complete until QC witness has signed the "Test Execution Record". 


\section{WHC-SD-WM-ATR-173 REV. 0 \\ HNF}

\subsection{MCCS EQUIPMENT}

The MCCS consists of three major components: 1) Imaging System, 2) Field Control Unit, and 3) the Mobile Platform.

6.1 Imaging System

Pan and Tilt unit (RJ Electronics model \#PTE-520)

- Camera and 8: 1 zoom lens - (RJ Electronics model \#RCS-2100)

- 75 Watt halogen light (RJ Electronics model \#AL-540)

- Camera Control Unit (RJ Electronics model \# CU 1150).

- $\quad$ Light Control Unit (RJ Electronics model \# CU 1150).

- Gas supply lines

- $170^{\prime}$ of camera control cable (RJ Electronics \#R4444)

6.2 Field Control Unit (FCU)

- $\quad$ Field Control Unit Enclosure

- 13" Color Video Monitor (Panasonic BT-H1350Y)

- Light Control Unit (RJ Electronics model \# CU 1150)

- Camera Control Unit (RJ Electronics model \# CU 1150)

- Pan and Tilt Control Unit (RJ Electronics model \# CU 1150)

- Electrical Safety Control Panel (9602HEF002)

- Keyboard

- VCR (Panasonic AG-1980P)

- Power Filter (SL Waber PH250) 
6.3 Mobile Platform

- Air Compressor (Thomas Model \#619CE44C)

- Dryer (Wilkerson Model \#X25)

- Regulator (Norgren Model \#R35-200-RNCA)

- Cable Reel (Hanney Model \#1500)

- $\quad$ 1/2" Air Hose (Bosflex Model \#55-1985-07)

- Hand Truck (Hanney Model \#4300)

\subsection{TEST CONDITIONS AND EQUIPMENT REQUIRED}

7.1 Test Conditions:

- The MCCS is completely assembled.

- The procedure has been approved and released.

- A QC witness shall be present.

- A pre-job safety meeting has been performed prior to starting the test.

7.2 Test Equipment

NOTE: SSI has the responsibility to provide the following equipment:

- Assembled Mobile Color Camera System (MCCS)

- Video Resolution Card

- A blank video cassette

- Stopwatch

- Electrical extension cords as necessary

- Leak detection liquid ("Snoop")

- Pressure Gauge (calibrated 0-30 psi)

- Flowmeter (calibrated 0-5 cfm) 


\subsection{ACCEPTANCE TEST}

The detailed steps of this ATP are provided in Appendix A. QC signatures and associated data shall be recorded as required in Attachment 1, Test Data Sheet. A copy of Appendix A along with Attachment 1, will be incorporated into the acceptance test report.

\subsection{DOCUMENTATION}

\subsection{Test Records}

9.1.1 All personnel involved in the performance of this test shall sign in Attachment 1 TEST EXECUTION RECORDS, to verify that the required people are in attendance for the test.

9.1.2 Test results shall be recorded by the SSI Test Engineer. All entries into this test procedure shall be made in black ink. Unless specific data is required, the signature of the person accepting the item will be entered in the blank provided to indicate compliance with the stated requirements or the successful completion of the given test step. Errors shall be corrected by crossing out the incorrect data with a single line and the correct response shall be written in the direct vicinity of the original item. The person making the correction shall initial and date the correction. Unacceptable conditions or readings shall be resolved in accordance with Section 3.0, EXCEPTIONS of Attachment 1. A complete working copy of this procedure and any exception records generated shall be maintained as a permanent record.

9.1.3 The Acceptance Test video tape shall be stored in the SSI video tape library and its unique reference number documented in the acceptance test report. 


\subsection{Exceptions}

An Exceptions sheet is attached in the event exceptions to the test are made when the test is being performed. All exceptions to the test are to be dispositioned and agreed to by all witnesses. Actions taken regarding disposition are noted on the exception sheet. During the performance of this test, errors in test may be encountered which require correction/adjustment to complete the test. Such corrections are to be noted in the ATP and listed as an exception in Attachment 1. 
WHC-SD-WM-ATR-173 REV. 0

HNF

APPENDIX A

MOBILE COLOR CAMERA SYSTEM

ACCEPTANCE TEST PROCEDURE STEPS 


\subsection{ACCEPTANCE TEST PROCEDURE}

NOTE: All data points and approval signatures shall be recorded in the spaces provided in Attachment 1.

\subsection{PREREQUISITES}

1.1.1 The Test Engineer shall verify that all the components to the Field Control Unit are properly connected prior to energizing the system, (see Figures 1 and 2).

Component Connections:

- Camera Control Unit

- Light Control Unit

- Electrical Safety Shutdown System

- Compressor

- Vitis II-GP System

- Video Recorder

- Color Monitor

Test Engineer sign off below that the proper connections are complete Test Engineer Date

QC Witness sign below verifying that instrumentation listed below has been calibrated and a current calibration sticker is affixed.

- Flowmeter (0-5 cfm) S/N

Cal. Date

- Pressure Gauge (0.30 psi) S/N Cal. Date

QC Witness Date

1.1.2 Pressurize each path (supply and return) to 5 - 25 psig and "Snoop" each fitting and resolve any significant leakage by tightening the fitting. If the leakage continues then replace the fitting. Test Engineer sign below that the system purge path is acceptable.

Test Engineer Date 
WHC-SD-WM-ATR-173 REV. 0

HNF

\subsection{PROCEDURE STEPS}

\subsection{ELECTRICAL SAFETY CONTROL PANEL}

$\mathrm{S} / \mathrm{N}$

NOTE: This portion of the test is to verify that all indicators located on the front face of the Electrical Safety Control Panel (ESCP) function properly. Time Delay Relay (TDR) unit will be set for two minutes to minimize time necessary for system power up.

2.1.1 POWER display located on the front face of the ESCP illuminates when the unit ON/OFF switch is moved to the ON position and power is available inside the box. Apply power to the unit and verify that the POWER light is functional.

2.1.2 Turn on the vacuum pump located on the Mobile Platform to allow for flow and pressure through the ESCP.

2.1.3 START/RESET display located on the front face of the ESCP operates when flow has been sensed. Press the START/RESET button and verify that the FLOW indicator illuminates.

2.1.4 PRESSURE \#1 and PRESSURE \#2 displays illuminate when pressure is sensed. With the START/RESET button previously activated, verify that the PRESSURE \#1 and PRESSURE \#2 indicators illuminate.

2.1.5 PURGING display illuminates when the ESCP begins the purge cycle. After pressing the START/RESET button, verify that the PURGING indicator is illuminated.

2.1.6 LOAD ENERGIZED display illuminates when the ESCP has enabled power output to the remaining MCCS. After the unit has completed its 2 minute purge cycle, verify the LOAD ENERGIZED indicator is illuminated.

2.1.7 SSI Test Engineer sign that steps 2.1.1 through 2.1.6 are acceptable.

Test Engineer Date 


\subsection{PURGE SYSTEM AND ESCP OPERATION}

NOTE: The total volume of the camera housing, light housing, pan-and-tilt, and hoses is $.6928 \mathrm{ft}^{3}{ }^{3}\left[.0162 \mathrm{ft}^{3}{ }^{3}\right.$ (camera housing volume) $+.0532 \mathrm{ft.}^{3}+$ (light housing volume) $+.0322 \mathrm{ft}^{3}$ (pan-and-tilt volume) $+.5912 \mathrm{ft}^{3}{ }^{3}$ (hose volume)]. Per NFPA 496 requirements, ten volumes of purge air $.6928 \mathrm{ft}^{3}$, must flow through the system. The Time Delay Relay (TDR) located in the Electrical Safety Control Panel (ESCP) will be adjusted to 8 minutes at a minimum flow rate of $.85 \mathrm{cfm},\left(.6928 \mathrm{ft}^{3} / .85 \mathrm{cfm}\right)$ to allow for $.6928 \mathrm{ft}^{3}$ total flow.

2.2.1 Place a flowmeter ( 0 - $5 \mathrm{cfm}$ range) in-line with the purge outlet supply fitting located on the rear of the ESCP.

2.2.2 Turn on the vacuum pump located at the mobile platform and press the START/RESET button located on the ESCP. Record the flowrate taken from the flowmeter. Verify flowrate is $.85 \mathrm{cfm}$ or greater. Once reading has been recorded, turn off vacuum pump and reconnect camera purge supply air hose to outlet supply fitting located on rear of ESCP.

Flowrate: $\mathrm{cfm}$

2.2.3 Turn on vacuum pump located at the mobile platform and press the START/RESET button located on the ESCP. Once purge cycle has begun, place hand over pressure relief valve and verify that flow is present at pressure relief valve located at the light housing of the camera system. Test Engineer's signature below will verify flow is present.

2.2.4 At the pressure relief valve located at the light enclosure, install a tube that is in line with a pressure gauge (Heise 0-30 psi range). Pressure gauge will read the system pressure that is present at the light enclosure and camera enclosure.

NOTE: Pressure measurement taken at pressure relief valve will cause system shutdown due to loss of flow which is measured by the flow switch located in the ESCP.

2.2.5 Turn on the vacuum pump located at the mobile platform and record the pressure reading from the Heise pressure guage that is in line with 
the pressure relief valve. Verify pressure falls in a range of 5 psi to 15 psi. Once reading has been recorded, turn off vacuum pump.

Pressure: 5-15 psi

2.2.6 Reset TDR located in the ESCP from 2 minutes to 8 minutes to verify that TDR will time out properly during a purge cycle.

2.2.7 Turn on vacuum pump located at mobile platform. Press the START/RESET switch located on the ESCP to begin purge cycle. With a stopwatch, time the duration of the purge cycle. Purge cycle will be complete when LOAD ENER GIZED indicator located on ESCP illuminates and power is provided to camera and lights. Record time of purge cycle and verify cycle duration is 8 minutes or greater. Adjust TDR as necessary repeat until purge cycle is $\geq 8$ minutes.

Time: minutes/seconds

2.2.8 Manually kink the purge air supply hose to the camera cutting off flow. Verify that system power down occurs after purge air flow is interrupted and that SYSTEM ENERGIZED, PRESSURE 1 and PRESSURE 2 indicator lights located on the ESCP are no longer illuminated.

Test Engineer Date

QC Date

2.2.9 Verify steps 2.2.1 through 2.2.8 are acceptable.

Test Engineer Date

QC Date

\subsection{DIFFERENTIAL PRESSURE SWITCHES}

NOTE: The camera enclosure of the Mobile Color Camera System houses two differential pressure switches that are monitored by the ESCP. Two switches were installed for redundant shutdown capability upon loss of pressure. The following steps will show that a backup pressure 
sensor is in place if one fails. A special switch box will be provided to allow one of the differential pressure switches to be disabled while the system is pressurized and operational.

2.3.1 Connect the test switch box in line with connector J3 located on the rear of the ESCP and connector J3 located on the rear of the Camera Control Unit.

2.3.2 Prior to running system through a purge cycle, check that both toggle switches of the test switch box are in the enable position for PS 1 and PS 2.

2.3.3 Turn on the vacuum pump located at the Mobile Platform. Press the START/RESET button located on the ESCP allowing system to begin a purge cycle. Purge cycle will be complete when LOAD ENERGIZED indicator is illuminated.

2.3.4 Once system is pressurized and LOAD ENERGIZED indicator is illuminated, manipulate the toggle switch for PS 1 to the "disable" position. Verify that system power is disabled.

2.3.5 Manipulate the PS 1 toggle switch back to the "enable" position.

2.3.6 Repeat step 2.3.3.

2.3.7 Once system is pressurized and LOAD ENERGIZED indicator is illuminated, manipulate the toggle switch for PS 2 to the "disable" position. Verify that system power is disabled.

2.3.8 Leave the PS 2 switch in the "disable" position and try to repressurize the camera system. Verify that ESCP will not allow system to begin repressurizing with PS 2 in the "disable" position.

2.3.9 Manipulate the PS 2 switch back to the "enable" position.

2.3.10 Manipulate the PS 1 switch to the "disable" position and try to repressurize the camera system. Verify that ESCP will not allow system to begin repressurizing with PS 1 in the "disable" position. 
WHe-SD-WM-ATR-173 REV. 0

HNF

2.3.11 Verify that steps 2.3 .1 through 2.3 .10 are acceptable.

Test Engineer

Date

QC Date

\subsection{CAMERA UNIT}

$\mathrm{S} / \mathrm{N}$

NOTE: During this portion of the test the Test Engineer shall verify each camera control is satisfactory and will then initial the space provided for each step.

2.4.1 Using remote camera zoom control, manipulate the zoom control to wide angle. VERIFY the zoom moves towards wide when operated towards "wide".

2.4.2 Manipulate the zoom control to telephoto. VERIFY the zoom moves towards telephoto when operated towards "telephoto".

2.4.3 VERIFY that the auto focus adjusts to far when viewing an object that's far.

2.4.4 VERIFY that the auto focus adjusts to near when viewing an object that's near.

2.4.5 Using the auto iris, adjust lighting to dim and VERIFY that auto iris adjusts accordingly.

2.4.6 Using the auto iris, adjust ambient lighting to bright and VERIFY that auto iris adjusts accordingly.

2.4.7 Bypass the auto focus control to manual control. VERIFY that the focus adjusts to near when focused on an object that is "near".

2.4.8 Using the far focus control. VERIFY that the focus adjusts to far when focused on an object that is "far".

2.4.9 Plug the video monitor and video recorder into the power source. Verify the video monitor and video recorder are operational. 
NOTE: This portion of camera test to be performed in a dark room using only the light provided with the MCCS system. The following steps shall be video taped and the resolution verified during play-back.

2.4.10 Determine the maximum distance and associated Light Control Unit (LCU) settings that the MCCS can:

2.4.10.1 Resolve a $1 / 32$ inch black line on an $18 \%$ neutral gray background.

$\overline{\text { Max. Distance }} \quad \overline{\text { LCU Setting }}$

2.4.10.2 Resolve a 1 inch black square on an $18 \%$ neutral gray background.

$\overline{\text { Max. Distance }} \quad \overline{\text { LCU Setting }}$

2.4.11 While the camera is focused on the standard resolution chart, verify that the picture is free of image defects such as ghost images, picture lag, distortion, hum, or smearing.

2.4.12 Play back the previously recorded taping of the resolution test. Verify that the video recorder operates properly and that the image is acceptable.

2.4.13 VERIFY steps 2.4.1 through 2.4.12 are complete.

Test Engineer Date

\subsection{PAN AND TILT}

NOTE: During this portion of the test the Test Engineer shall VERIFY each panand- tilt control is satisfactory and will then initial in the space provided for each step.

2.5.1 Using the remote pan control, pan in the clockwise direction until stop is reached. Record the encoder readout for the position of the camera.

Encoder reading: degrees 
WHC-SD-WM-ATR-173 REV. 0

hiNF

2.5.2 Pan in the counterclockwise direction until stop is reached. Record the encoder readout.

Encoder reading: degrees

2.5.3 VERIFY, using the readings from step 2.3.1 and 2.3.2 that the panning operation has covered 350 degrees.

Overall reading: degrees

2.5.4 Tilt the camera to the straight down position. VERIFY that the camera is pointing 90 degrees downward from the horizontal position and the electronic brake holds. Record the encoder readout.

Encoder reading: degrees

2.5.5 Tilt the camera up to the extreme upward position. VERIFY that the camera is 60 degrees up from the horizontal position and the electronic brake holds. Record the encoder readout.

Encoder reading:_______egrees

2.5.6 VERIFY using the encoder readings from steps 2.3.4 and 2.3.5 that the tilt has a range of 150 degrees.

Overall reading; degrees

2.5.7 De-energize the pan and tilt unit and VERIFY that the camera returns to the downward position by gravity or with light manual pressure.

2.5.8 VERIFY steps 2.5.1 through 2.5.7 are acceptable.

Test Engineer

Date

\subsection{EXCEPTIONS}

Any exceptions to this ATP shall be recorded in the EXCEPTIONS section provided in Attachment 1. The EXCEPTIONS section will only require applicable signatures if there was an exception to a step or a section of this ATP. The section, step number, a description of the exception, and a resolution to the exception will be identified as part of this section. 


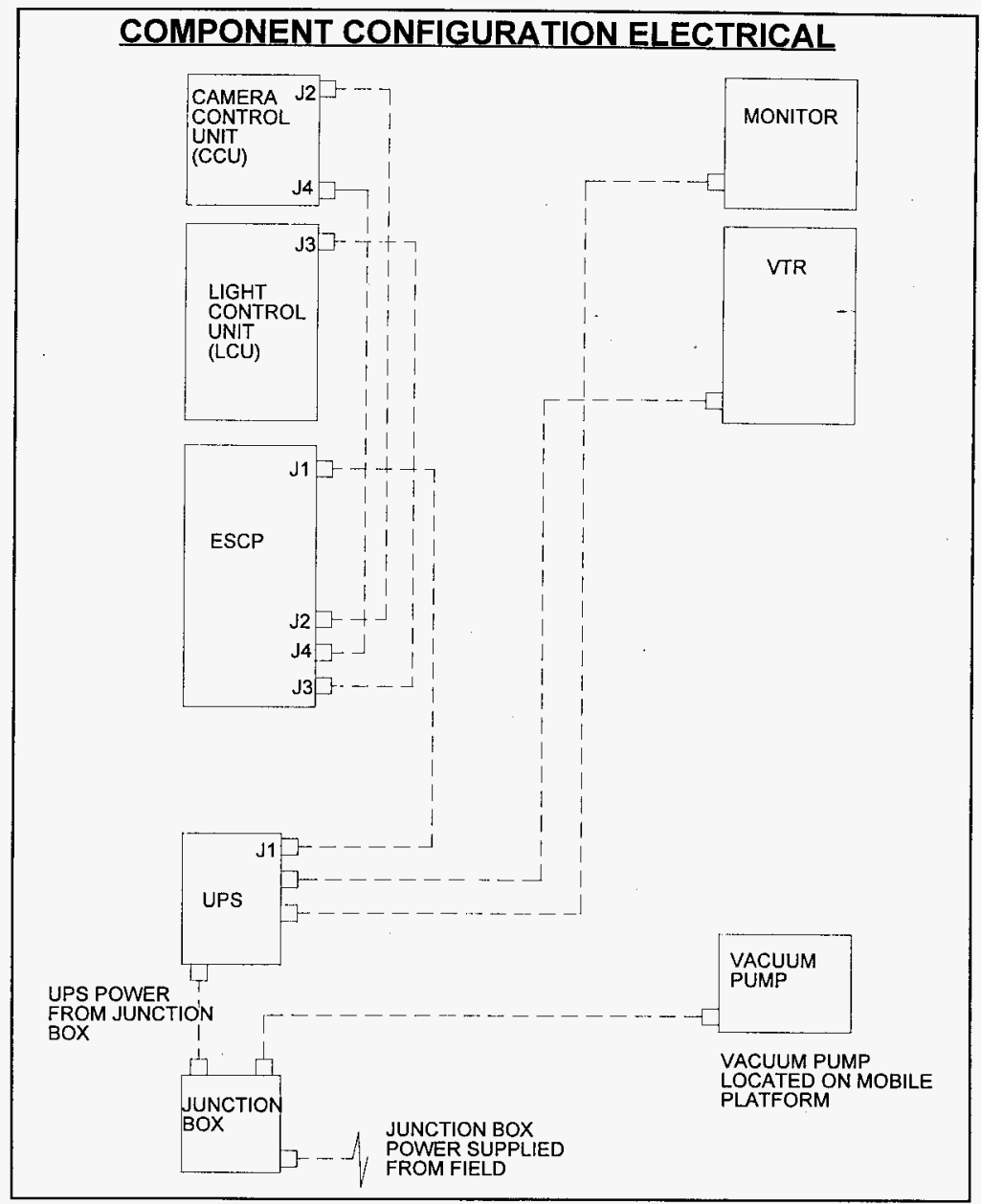

Figure 1 


\section{COMPONENT CONFIGURATION - PNEUMATIC}

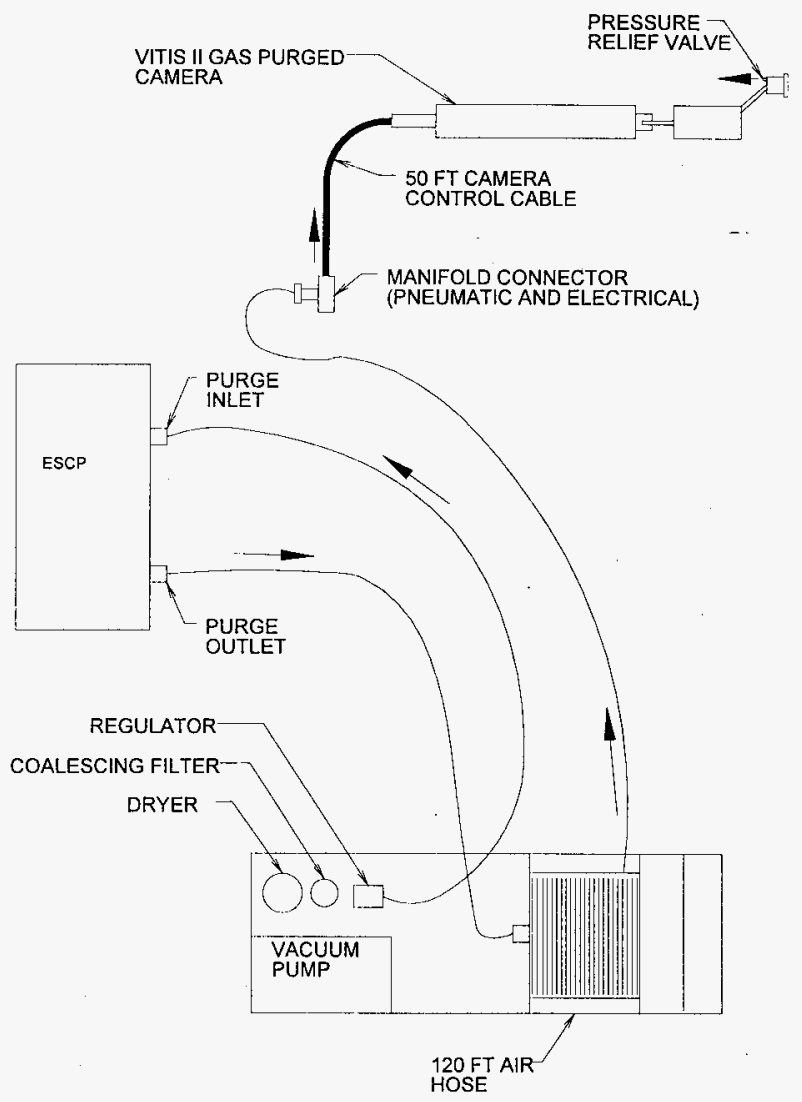

MOBILE PLATFORM

Figure 2 


\section{$\cos _{21} 197$ \\ WXC-SD-WM-ATR-173 \\ HNF \\ Rev. 0}

APPENDIX B

ACCEPTANCE TEST DATA

B1 
WHC-SD-WM-ATR-173 REV. 0

HNF

$S / N$ macs $\# 1$

\section{ATTACHMENT 1}

TEST DATA SHEET

\section{TEST EXECUTION RECORD}

Test Personnel Attendance Sign In:

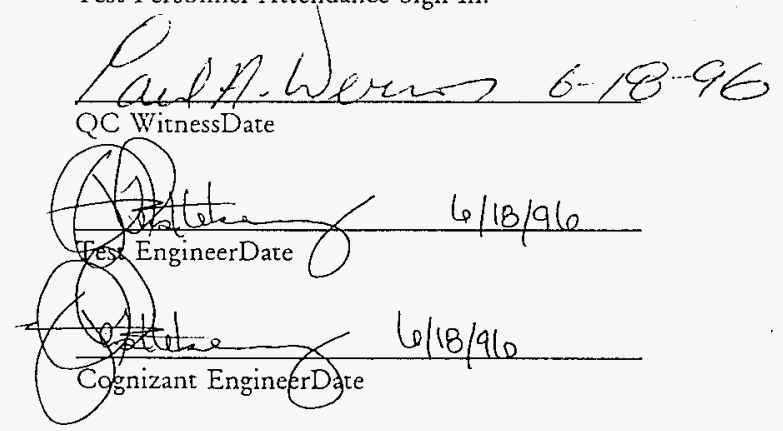

Other Personnel Present:

Signature

Print Name

Position

Date 
WHE-SD-WM-ATR-173 REV. 0

INF

S/N Macs 1

Section 1 - Acceptance Test Procedure

Step 1.1 .1 Flowmeter S/N $\frac{545-38-13-057}{5-5 \mathrm{cfm}}$ Cal. Date $5 / 24 / 97$ due

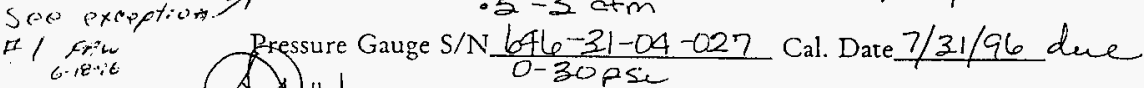
$\frac{6 / 1896}{\text { Date }}$

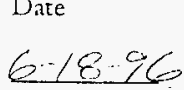

Date

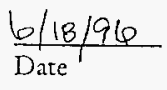

Step 1.1 .2

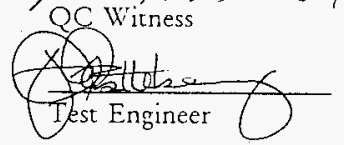

Section 2.0 Procedure Steps

Step $2.1 \quad$ Electrical Safety Control Panel (ESCP) s/N_OCO)

Step 2.1 .7 $\frac{6 / 18 / 916}{\text { Date }}$

Section 2.2 Purge System and ESCP Operation

Step 2.2.2

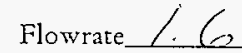
cf m

Step 2.2.5

Pressure $5: 2$ (5-15) psi

Step 2.2.7 Time 9 min $/ 52 \leq e c$._minute s/seconds

Step 2.2.8

Step 2.2 .9
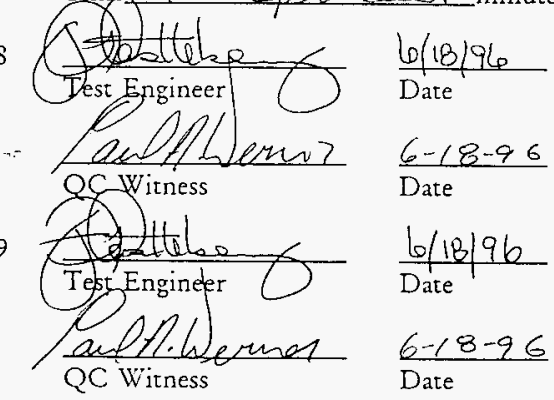

Steps 2.3 .8 and 2.3.10 33 so exception 7 a enters 
WHE-SD-WM-ATR-173 REV. 0

\section{Section 2.3 Differential Pressure Switches}

Step 2.3.11

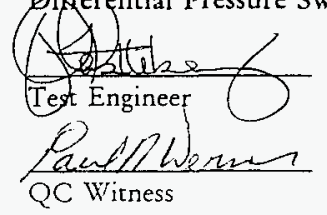

$\frac{6 / 18196}{\text { Date }}$

6.18 .96 soc expestent2

Date

Section 2.4 Camera Unit

Step 2.4 Camera Unit S/N H?CCSST

Step 2.4.10.1 $\frac{43 \mathrm{ft}}{\text { Max. Distance }}$ $\frac{100 \%}{\text { LCU Setting }}$ distance abtamable distance abtainable

Step 2.4.10.2

$43 \mathrm{ft}$ $100 \%$ within the shap.

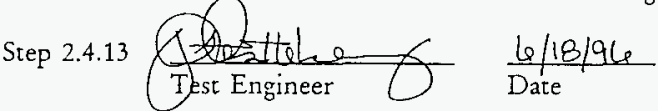

Section 2.5 Pan and Tilt

Step 2.5.1 Encoder Reading_ 359 degrees

Step 2.5.2 Encoder Reading $\mathrm{OOO}$ degrees

Step 2.5.3 Overall Reading 359 degrees

Step 2.5.4 Encoder Reading 148 degrees

Step 2.5.5 Encoder Reading $301 \quad$ degrees

Step 2.5.6 gyexall Reading 153 degrees

Step 2.5 .8

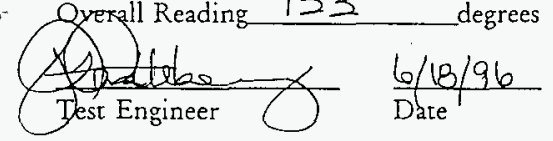


WHC-SD-WM-ATR-173 REV. 0

HNF

$S / N$ mocs $\# 1$

Section 3.0 Exceptions

\begin{tabular}{|l|l|l|l|}
\hline \hline Section & Step & Description & Resolution \\
\hline 1 *1 $1.1 .1 \quad$ PREREQuSTES a flommeter with a \\
\hline
\end{tabular} used. This is quithin the iange needed for tisting.

*22.32.3.8 Piffrential

With PS-2 Suntchin 2.3.10 Pressme buitches the "dirable" pastion Camora will pressurize, homener purge system liel nat time out and allow camera to eneiguze.

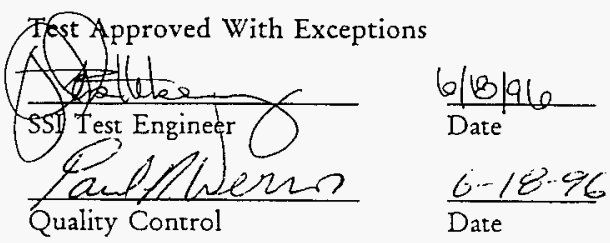

B5 
WНE-SD-WM-ATR-173 REV. 0

HNF

ATTACHMENT 1

S/N Mecs \#2

TEST DATA SHEET

\section{TEST EXECUTION RECORD}

Test Personnel Attendance Sign In:

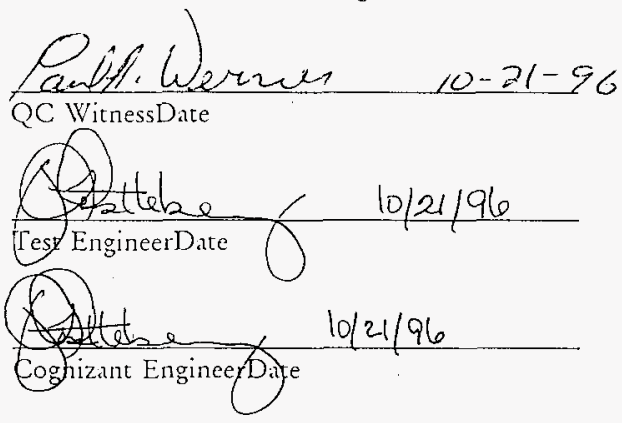

Other Personnel Present:

$\begin{array}{llll}\text { Signature } & \text { Print Name } & \text { Position }\end{array}$

$x-$

-

B6 
WHE-SD-WM-ATR-173 REV. 0

NF

Section 1 - Acceptance Test Procedure

S/N Macs 2

Step 1.1.1 Flow meter S/N $545-28-13-057$ Cal. Dire $5-24-96$ (Test exception $\#$ i),

Pressure Gauge $5 / \mathrm{N}(246-31-04-029)$ Cal. Dare $8-13-96$ $10 / 21 / 96$ Date

$10-21-96$

Date

Step 1.1 .2

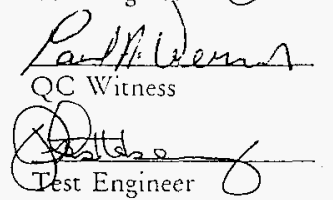

$\frac{10 / 21 / 96}{D+5}$

Section 2.0 Procedure Steps

Step 2.1 Electrical Safety Control Panel (ESCP) S/N_ 0002

Step 2.1 .7

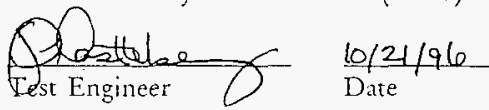

Section 2.2 Purge System and ESCP Operation

Step 2.2.2 Flowrate_1.6.5 cf in

Step 2.2.5 Pressure_ 6.5 $(5-15)$ psi

Step 2.2.7 Time $9 \mathrm{~min} / 2 \mathrm{sec}$. minutes/ seconds

Step 2.2 .8

Step 2.2 .9

$$
\frac{10 / 21 / 96}{\text { Date }}
$$$$
\frac{10.21-96}{\text { Date }}
$$$$
\text { lo /2/96 }
$$$$
\text { Date }
$$

$\frac{1021-96}{\text { Date }}$

B7 


\section{HNF}

Section 2.3 Differential Pressure Switches

$\sin \operatorname{MCCS}^{\# 2}$

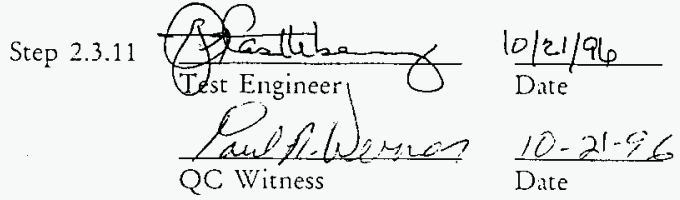

Section 2.4 Camera Unit

Step 2.4 Camera Unit

S/N Mces $\# 2$

Step 2.4.10.1

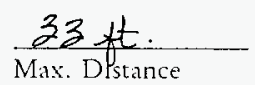

$100 \%$

LCU Setting

Step 2.4.10.2

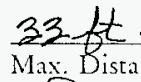

$\frac{100 \%}{\text { LCU Setting }}$

Step 2.4 .13

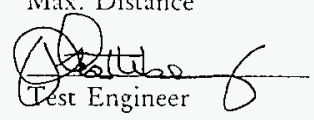

$\frac{10 / 21 / 96}{\text { Date }}$

Section 2.5 Pan and Tilt

Step 2.5.1 Encoder Reading__ 359 degrees

Step 2.5.2 Encoder Reading OOC_degrees

Step 2.5.3 Overall Reading 359 degrees

Step 2.5.4 Encoder Reading 192__degrees

Step 2.5.5 Encoder Reading 41 degrees

Step 2.5.6. Overall Reading 151 degrees

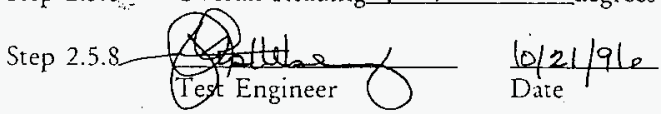


WHC-SD-WM-ATR-173 REV. 0

HNF

Section 3.0 Exceptions

S/N MCCS \#2

\begin{tabular}{|l|l|l|l|}
\hline \hline Section & Step & Description & Resolution \\
\hline
\end{tabular}

1.0

1.1 .1

Step 1.1.1 specifies a flowmeter with a 0 to $5.0 \mathrm{CFM}$ rating to be used. A flowmeter with a .5 to 4.35 CFM range was used instead.

Resolution: This flowmeter is within the range of flows being measured and is considered acceptable for use.

Step 2.3.10 reads as follows: "Manipulate the PS-1 switch to the "disable" position and try to repressurize the camera system. Verify that ESCP will not allow system to begin repressurizing with PS-1 in the "disable " position.

Resolution: Substitute the term repressurizing with the term re-encrgize.

$2.0 \quad 2.3 .1$

Prototype ESCP was tested with pressure sensor connector being identified as connector J3. Non-prototype ESCP now identifies the pressure sensor connector as J4.

Resolution: Substitute reference to connector $\mathrm{J} 3$ with connector number $\mathrm{J} 4$.

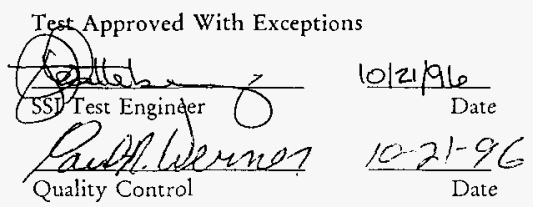


ATTACHMENT 1

TEST DATA SHEET

\section{TEST EXECUTION RECORD}

Test Personnel Attendance Sign In:

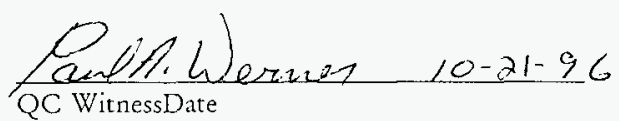
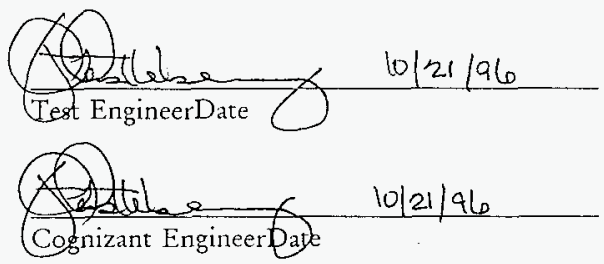

Other Personnel Present:

Signature

Print Name

Position

Date 
Section 1 - Acceptance Test Procedure S/NnICCS \#3
Step 1.1.1 Flowmeter S/N $545-28-13-0257$ Cal. Date $5-24-96$ (Test exceptiont/) Pressure Gauge S/N6x/6-31-04-029 Cal. Date8-13-86
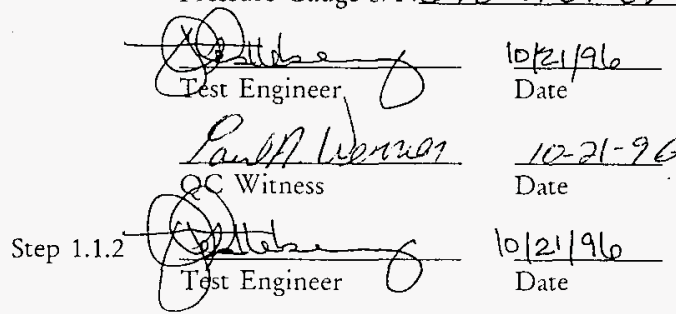

Section 2.0 Procedure Steps

Step 2.1 Eleetrical Safery Control Panel (ESCP) S/N 0005

Step 2.1.7

Section 2.2 Purge System and ESCP Operation

Step 2.2.2 Flowrate_ $/ 6 \quad \mathrm{cfm}$

Step 2.2.5 Pressure_ 6.5 (5-15) psi

Step 2.2.7 Time $9 \mathrm{~min} / 8 \mathrm{sec} \quad$ minutes/seconds

Step 2.2.8

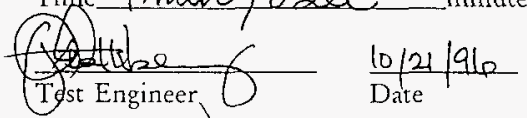

- PadAl Doms $\frac{10.2190}{\text { Date }}$

Step 2.2.9

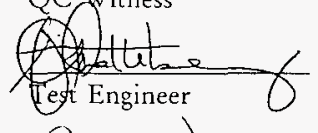

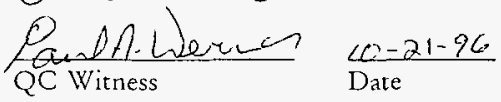


WHE-SD-WM-ATR-173 REV. 0

HNF

Section 2.3 Differential Pressure Switches

Step 2.3.14 $\frac{10 / 21 / 96}{\text { Date }}$

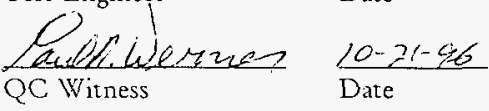

Section 2.4 Camera Unit

Step 2.4 Camera Unit

S/N Mocs \#3

Step 2.4.10.1

$\frac{3.3}{\text { Max. Distance }}$

$\frac{100 \%}{\text { LCU Setting }}$

Step 2.4.10.2

3.3

$100 \%$

Step 2.4.13

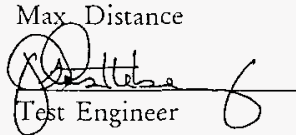

LCU Setting

$\frac{10 / 21 / 96}{\text { Date }}$

Section 2.5 Pan and Tilt

Step 2.5.1 Encoder Reading $3.5^{-9}$ _ degrees

Step 2.5.2 Encoder Reading OOO degrees

Step 2.5.3 Overall Reading_.3.59_degrees

Step 2.5.4 Encoder Reading 193 degrees

Step 2.5.5 Encoder Reading_ $\quad 1.3$ _. degrees

Step 2.5.6. Oyerall Reading 150 degrees

Step 2.5.8

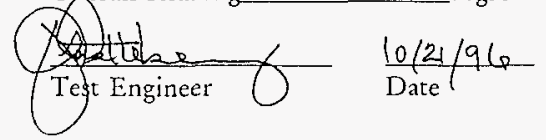




\begin{tabular}{|l|l|l|l|}
\hline Section & Step & Description & Resolution \\
\hline
\end{tabular}

1.0

1.1 .1

2.0

2.0 2.3.1
Step 1.1.1 specifies a flowmeter with a 0 to $5.0 \mathrm{CFM}$ rating to be used. A flowmeter with a .5 to 4.35 CFM range was used instead.

Resolution: This flowmeter is within the range of flows being measured and is considered acceptable for use.

Step 2.3.10 reads as follows: "Manipulate the PS-1 switch to the "disable" position and try to repressurize the camera system. Verify that ESCP will not allow system to begin repressurizing with PS-1 in the "disable " position.

Resolution: Substitute the term repressurizing with the term re-energize.

Prototype ESCP was tested with pressure sensor connector being identified as connector J3. Non-prototype ESCP now identifies the pressure sensor connector as $\mathrm{J} 4$.

Resolution: Substitute reference to connector $\mathrm{J} 3$ with connector number $\mathrm{J} 4$.

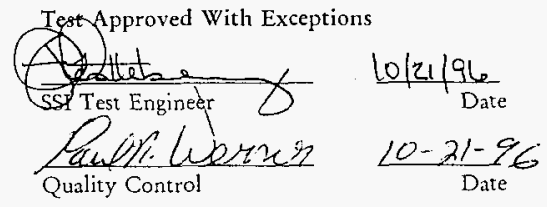




\section{WHE-SD-WM-ATR-173}

HNF Rev. 0

APPENDIX C

MANUFACTURER TEMPERATURE DATA

C1 


\section{R.J, Electronics 5504 Val View Dr. SE \\ Turner, OR 97392 \\ Tel. 503-743-3709 \\ Fax. 503-743-3707}

\section{TELEFAX COVER SHEET}

To:

Company:

Fax \#:

From:

Date:

Number of pages;:

Re:
Jim Castlebury

Westinghouse Hanford Co.

509-376-9967

Roy Bennett

05-08-96

4

Temperature tests on quick deployment system

$\mathrm{Hi}$,

Thanks for your Fax, please find attached our notes on the temperature tests.

The AL- 540 notes were conducted by Bruce on the lamp only, the RCS-2015 notes are mine using the complete system.

I hope this helps.

Roy 


\section{RCS-2015 Light Temperature Data}

\begin{tabular}{|c|c|}
\hline Ambient Temperature & 21 degrees $C$. \\
\hline Gas pressure & 3.5 PSI measured at gas input manifold \\
\hline Camera system & Operating \\
\hline Lamp voltage & 12 volt, 75 Watt lamp operating at $14.2 \mathrm{v}$ \\
\hline Point of measurement & On top side of light with lamp horizontal \\
\hline Pressure sensors & Closed \\
\hline Pressure relief valve & Venting \\
\hline Gas temperature at pressure relief valve & 92 degrees $\mathrm{C}$. after 2 hours \\
\hline $\begin{array}{c}\text { TMME } \\
\text { [minutes] }\end{array}$ & $\begin{array}{l}\text { TEMPERATURE } \\
\text { [degrees C] }\end{array}$ \\
\hline 0 & 21 \\
\hline 5 & 53 \\
\hline 25 & 93 \\
\hline 30 & 107 \\
\hline 40 & 115 \\
\hline 45 & 117 \\
\hline 60 & 119 \\
\hline 70 & 117 \\
\hline 80 & 118 \\
\hline 120 & 117 \\
\hline
\end{tabular}


The temperature rise of the AI-540 light was reasured at the Crestone Products, Inc. facility on $1 / 18 / 96$.

1. The lamp was operated at 12,0 volts

2. Regulated compressed air was used tor cooling. The pressure measured at the lamp input was adjusted to 3 psi, and monltored with a 0-10 psi gauge.

3. The lamp case temperature was measured with a PTC INSTRUMENTS (Pacific Transducer Corp., 2301 Federal Avenue, Los Angeles, CA $90064-1482$ (310) 478-1134) model $488 \mathrm{C}$ spring held pipe-surface thermometer with a range from $20^{\text {to }} 260$ degrees Centigrade. The temperatue was measured on the top surface in the middle of the light with the light in a horizontal position (beam horizontal).

4. The ambient temerature was measured with a Radio shack model 63-859 digital indoor-outdoor thermometer, and the starting temperature was verified as the same as with the PTC thermometer.

5. With pressure maintained at $3 \mathrm{psi}$, the lamp reached an equilibrium temperature of 94 degrees $C$ after about 45

- minutes. With an ambient temperature of 16 degrees, the temperature rise above amblent at equilibrium was 78 centigrade degrees.

6. With an input pressure of $3 \mathrm{psi}$, the air flow through the lamp was approximately $4.2 \mathrm{GPM}$.

7. After one hour, the gas was turned off, and the lamp surface temperature rose and stabilized at 146 degrees after 35 minutes. This corresponds to a temperature rise above ambient of 130 Centigrade degrees with no gas flow to the lamp.

8. A copy of the raw data is attached. 
$12 / 17 / 199614: 45 \quad 5033624754$ R.J ELECTRONICS

WHE-SD-WM-ATR-173 REV. 0

HNF

$1 / 18 / 96$ AL-540 $164-T$
VOGASE 12.00 PRESS URE O LAMP 13 Ps; $7.5 \mathrm{sac} / \mathrm{se}$

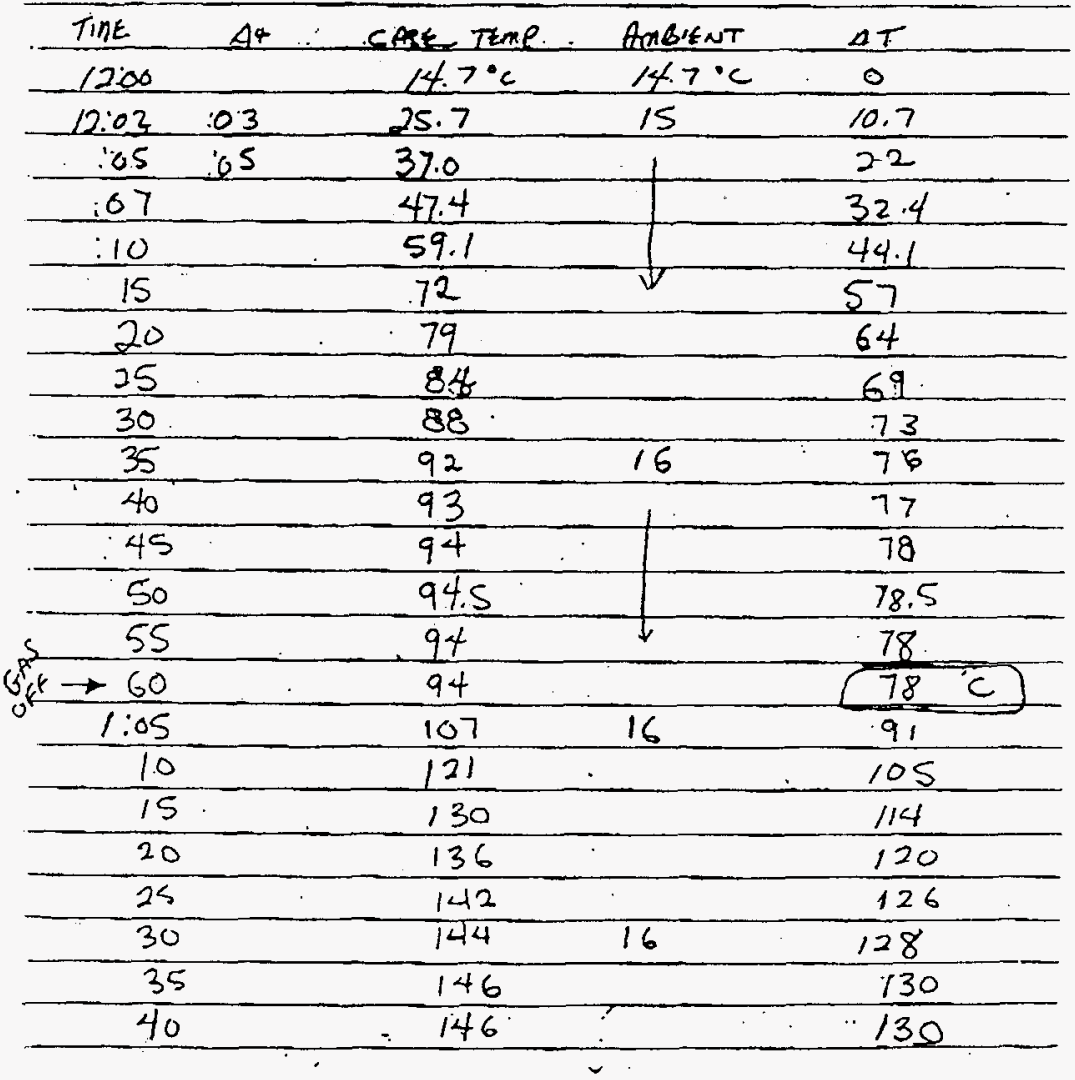

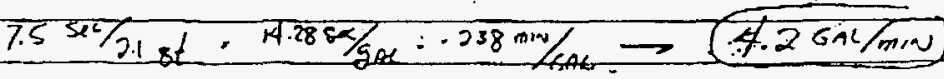

C5

TOTAL P.O: 